\title{
The warden attitude: an investigation of the value of interaction with everyday wildlife
}

\author{
Michael Brock ${ }^{a}$, Grischa Perino ${ }^{\text {b) }}$ and Robert Sugden ${ }^{\text {a) }}$ \\ a) School of Economics, University of East Anglia \\ b) Corresponding author: Department of Socioeconomics, University of Hamburg \\ Welckerstr. 8, 20354 Hamburg, Germany \\ grischa.perino@wiso.uni-hamburg.de \\ phone: +49 $4042838-8767$
}

\begin{abstract}
Using a discrete choice experiment, we elicit valuations of engagement with 'everyday wildlife' through feeding garden birds. We find that bird-feeding is primarily but not exclusively motivated by the direct consumption value of interaction with wildlife. The implicit valuations given to different species suggest that people prefer birds that have aesthetic appeal and that evoke human feelings of protectiveness. These findings suggest that people derive wellbeing by adopting a warden-like role towards 'their' wildlife. We test for external validity by conducting a hedonic analysis of sales of bird food. We discuss some policy implications of the existence of warden attitudes.
\end{abstract}

Keywords: use value, everyday wildlife, discrete choice experiment, nature connectivity, warden attitude, garden birds, hedonic

JEL code: Q26, Q57, H41 


\section{Introduction}

Engagement with the natural environment holds the potential to substantially enhance human well-being in numerous ways. Many of these benefits depend on direct exposure to, and sometimes active interaction with, the natural environment. This study focuses on this source of benefit by investigating individuals' valuation of direct engagement with everyday wildlife through feeding common garden birds. We use a discrete choice experiment to elicit valuations of engagement with different bird species, and try to uncover the motivations that underlie this engagement. We check for broad consistency with a hedonic analysis of bird food purchases from a UK producer and retailer.

We use the term everyday wildlife to refer to wildlife that people are likely to encounter relatively frequently (and perhaps not even notice) as a background feature of ordinary activities such as gardening, travelling to work or walking a dog. The intended contrast is with what we will call iconic wildlife - wildlife that is perceived as special by virtue of its being rare, endangered or spectacular, and which is more likely to be encountered by watching television documentaries, travelling to remote areas or visiting dedicated nature reserves. Most wildlife valuation studies have focused on wildlife with the latter features, or on sites with special characteristics. ${ }^{1}$ Although this distinction is a matter of degree and involves more than one attribute, we think it is significant for environmental policy. Our study was motivated by the hypothesis that interaction with everyday wildlife creates a kind of use value that is fundamentally different from the value created by the conservation of endangered species.

Engagement with the natural world, or 'nature connectivity' (Dutcher et al, 2007), exhibits many of the qualities identified in the literature of subjective well-being as beneficial to lasting life satisfaction. It is one aspect of the general concept of interconnectedness, which is common to many actions that enhance subjective well-being, including involvement with

\footnotetext{
${ }^{1}$ See e.g. Navrud \& Mungatana (1994), Loomis \& White (1996), White et al. (1997), Kontoleon \& Swanson (2003), Christie et al. (2006), Jacobsen et al. (2008) and Morse-Jones et al. (2012). There is a similar trend in conservation and conservation biology (Miller and Hobbs, 2002; Dunn et al., 2006) which is not uncontroversial (Gaston and Fuller, 2008). One exception to this is Clucas et al. (2015), who assess the total economic value of two common songbird species in Berlin and Seattle. They use the contingent valuation method to elicit the willingness-to-pay of survey participants to increase the population of two common songbirds by an unspecified amount, and combine this with self-reported expenditure on bird food. Another exception is Farmer et al. (2011), who use a hedonic study of house prices to estimate the value of an increase in a local bird diversity index.
} 
religion (Frey \& Stutzer, 2010), community (Dutcher et al, 2007) and wider society.

Furthermore, the repetition associated with everyday wildlife interactions potentially induces positive feelings of responsibility (Jacobssen et al, 2008), routine (Diener \& BiswasDiener, 2011) and achievement of success under uncertainty (Dolan et al, 2008). We will refer to this bundle of subjective responses to everyday wildlife as the warden attitude. The underlying idea is that individuals gain satisfaction from being actively involved with wildlife in ways that they can perceive as 'helping' or 'nurturing' living things that are dependent on them. In this sense, ordinary individuals are assuming the role of a warden in relation to wildlife that they see as 'theirs'. These kinds of satisfaction are in many ways more similar to those derived from keeping pets (Johnson, 2011) or houseplants (Rappe, 2005) than to the feelings associated with passively looking at rare wildlife in a protected nature reserve, or with giving money to an environmental charity. These organisations do attempt to actively 'involve' donors through mechanisms such as newsletter updates or adoption packs, but even these initiatives do not offer the direct type of interaction which engagement with everyday wildlife can provide. Garden bird feeding is one of the most readily available ways of taking on a warden role in relation to wild animals. Davies et al. (2009) report that $48 \%$ of UK households engage in this activity.

Satisfying individuals' desires for warden-like engagement with nature can require very different policy interventions than those that are needed to conserve iconic wildlife or wild landscapes. For example, current UK policy prioritises 'brownfield' and urban in-fill development ahead of that on 'greenfield' or rural sites, with the aim of protecting rural open space against urban expansion. The environmental benefits of such policies are liable to be achieved at the expense of opportunities for urban populations to engage with everyday wildlife around their homes and in their local neighbourhoods. In this respect, our study complements existing work investigating the value of private gardens (Gibbons et al., 2014) and of urban green space (Perino et al., 2014) in the UK. Another example concerns the distribution of conservation effort between different species. Current EU and UK conservation policy emphasises biodiversity and concentrates resources on 'priority species', usually characterised by small and endangered populations with highly specific habitat requirements. Such policies cater to the existence value of iconic wildlife and to passive kinds of use value, such as recreational wildlife viewing. In contrast, satisfying people's 
desire for more direct engagement with nature requires relatively large populations of species that can adapt to urbanised environments. Viewed in this perspective, the current trend of decline in the abundance and biomass of common species in Europe (Hole et al., 2008; Inger et al., 2015) is a matter of serious concern.

We see the primary policy relevance of our work in relation to these strategic issues, rather than as providing guidance on specific details of environmental management. For example, our choice experiment separately identifies individuals' valuations of interacting with six different species of birds. The main value of this exercise is not in providing evidence to allow urban green space to be designed to favour the habitats of some bird species rather than others. It is as a way of teasing out the nature of the value that individuals derive from engagement with everyday wildlife.

From a methodological point of view, the fact that we are investigating active engagement with wildlife allows us to avoid some common problems of stated preference studies. Stated preferences techniques have been found unreliable when participants lack knowledge of or experience with the object to be valued (Nunes and Bergh, 2001) or the valuation mechanism (Bateman et al., 2008). In our study both the good to be valued (engagement with garden birds) and the payment vehicle (purchase of bird food) are common activities; most of our participants reported experience of both. Because bird food is sold commercially, the prices at which different products are sold provide rough checks on the credibility of respondents' reported willingness to pay for the good that is being studied. This feature allows us to conduct a robustness check using revealed preference data.

The remainder of the paper is structured as follows. Section 2 outlines the methodology, describing how the choice experiment was designed. Section 3 describes the empirical model used in the analysis. Section 4 presents the results and discusses the findings. Section 5 contains a partial revealed preference external validity test. The last section concludes and suggests some directions for future research.

\section{The discrete choice experiment: survey design}


The survey contained three sections in the following order: the choice experiment, a bird identification quiz to test respondents' knowledge about birds, and a questionnaire to collect socio-demographic information and to elicit respondents' attitudes to bird-feeding. A short version of the instructions ${ }^{2}$ for the choice experiment and details of the quiz and questionnaire are reproduced in Appendices B, C and D respectively. A sample choice set appears as Figure 4 later in the paper.

\subsection{The choice experiment: attributes}

Based on Lancaster's characteristics approach (Lancaster, 1966), discrete choice experiments assume that the value of a good can be established through its constitutive attributes. The value of each attribute is assumed to be independent of how they are bundled. In our case, the attributes are the species and number of birds attracted and fed by a particular episode of bird feeding, whether the birds fed are observed by the person feeding, the nutritional value of the feed, the price of the feed, and whether the price includes a donation to the conservation of a regionally occurring endangered bird species. Each choice set included a baseline option of not feeding birds and two feeding options. Described in greater detail below, these attributes were presented across options in a way which ensured choice-set orthogonality.

The survey was carried out in Norwich, a medium-sized city in the largely rural county of Norfolk in eastern England. The bird species used in the choice experiment were chosen to be representative of those that might be seen in gardens in Norfolk at any time of the calendar year. As will be discussed later in the paper, their selection also sought to test whether feeding motivations could be attributed to warden attitudes as opposed to other reasons such as appearance or abundance. Figure 1 displays the six bird species included in the survey. ${ }^{3}$ The selection was based upon the 2012 Big Garden Bird Watch (BGBW) Survey organised by the Royal Society for the Protection of Birds (RSPB), one of the largest wildlife charities in the UK. The BGBW is the largest wildlife data collection scheme in the UK and is based on public participation. Annually, it invites the public to log both the diversity and frequency of bird species witnessed in their gardens for one hour over a pre-determined

\footnotetext{
${ }^{2}$ As given to participants in printed form when making their choices. The full instructions used to introduce participants to the choice experiment are available as supplementary material.

${ }^{3}$ The electronic version of this paper shows all figures in their original colours.
} 
weekend in January. Thanks to the dataset's geographical species mapping, Norfolk data could be isolated.

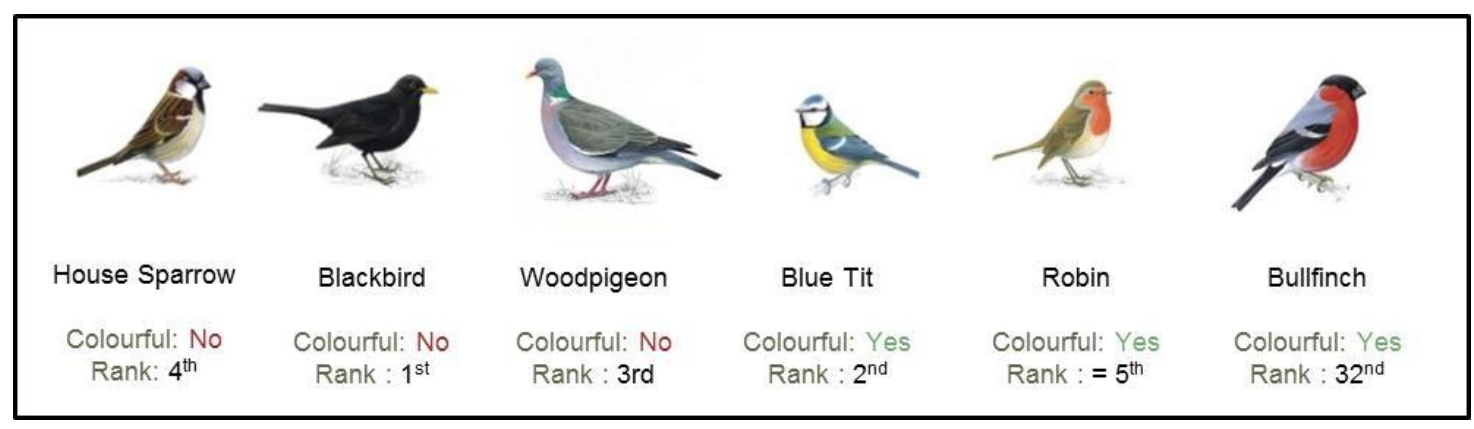

Figure 1: The bird species and their rank based on observed occurrences in Norfolk gardens (RSPB 2012).

The 'ranks' shown in Figure 1 refer to the relative frequency with which each species was observed in the BGBW survey (see the last column in the table in appendix A). A ranking of " 1 st" refers to the bird which was most frequently seen by participants. Consequently, the six species in our experiment included the five most frequently seen species (blackbird, blue tit, wood pigeon, house sparrow and robin). We expected that most respondents would be familiar with these species and, if interested, would be able to watch and interact with them regularly. By contrast, the other species in the experiment, the bullfinch, ranked a lowly $32^{\text {nd }}$. Norfolk residents were about sixty times more likely to encounter blackbirds in their gardens, and twenty-three times more likely to encounter robins, than bullfinches. This disparity was deliberate and is used to test for a premium on rarity. Such a premium has been found for charismatic species (Hanley et al, 1998b; Jacobsen et al., 2008), but we wanted to investigate whether this finding would extend to everyday wildlife. Alternatively, if the value of local wildlife stems from repeated interaction and a warden role, rarity might reduce a species' value.

Whether a species is visually pleasing is another potential indicator of an individual's valuation (Metrick \& Weitzman, 1996). The six species in our experiment exhibit different degrees of aesthetic appeal. The three birds on the right-hand side of Figure 1 possess a greater degree of vibrancy in their plumage, which one might expect would make them 
more visually attractive. Woodpigeons are widely perceived as a pest species among gardening and agricultural communities, and so it seemed worthwhile to include this 'undesirable' bird.

\begin{tabular}{|c|c|}
\hline Rating & \begin{tabular}{c} 
Description \\
garden \\
\hline
\end{tabular} \\
\hline $\begin{array}{c}\text { This species will not come to your } \\
\text { 1 bird of this species to come to } \\
\text { your garden }\end{array}$ \\
\hline
\end{tabular}

Figure 2: Bird frequencies and their visual representation in the experiment.

In line with recommendations from the literature (Kontoleon \& Swanson, 2003; Bateman et al., 2009), the birds attracted by a particular bird food option were displayed through the same visual images reproduced in Figure 1. Using coloured pictures of the birds gave each choice set a more realistic ambience, making it easier for participants to visualise particular combinations of birds in their own gardens. Furthermore, the use of images did not exclude or restrict participants whose lack of knowledge with respect to species names would otherwise have inhibited their ability to express well-informed preferences. The six species were never identified by name in the choice experiment. Throughout the survey species were identified only by these pictures. This property of the experiment was intended to model the fact that a person who feeds birds normally knows what those birds look like, but may or may not know which species they belong to. This methodology rests on the assumption that participants are able to link the pictures in the experiment with their visual experiences of real birds, whatever their mental representations of those experiences may be, but it does not require any particular assumptions about their knowledge of birds. For example, if a participant recognises blackbirds as a distinct category of birds when she sees them in her garden, then our methodology requires that she recognises our pictures of 
blackbirds as pictures of the birds from the same category. If, were she to see a bullfinch, she would classify this as 'a medium-sized red bird I haven't seen before', then our methodology requires that she would classify our bullfinch picture in the same way.

This feature of our design is important for the interpretation of our concept of 'rarity'. Participants were not explicitly informed that the bullfinch was much rarer than the other five species. Thus, their reported valuations for bullfinches reflect whatever beliefs they actually held, in the light of their actual experiences, about the likelihood of encountering the (known or unknown) species of bird shown in our bullfinch picture. We are interested in whether the objective rarity of a species - the fact that people rarely encounter it increases the valuation that people attach to engagement with it.

Figure 2 shows how bird numbers were presented to participants. Each option was described in terms of the numbers of birds of each species attracted as a result of one episode of dispensing food. The numbers were chosen to be broadly consistent with the frequencies recorded in the BGBW dataset. For reasons of credibility, the baseline option of not feeding did not involve a complete absence of birds; it was given the 'one bird' rating for two particularly common and uncharismatic species - the blackbird and the house sparrow. In every feeding option, these two species had at least the 'one bird' frequency rating. Another ornithological consideration was to ensure that options showed birds at levels broadly consistent with their social behaviour. For instance, robins are highly territorial and so constructing a choice set which included more than a single bird might have been seen as contradictory to this element of their behaviour.

The survey was also designed to investigate the extent to which people's values were derived from watching birds feed. To achieve this, the experiment included options in which some birds would eat the food dispensed but would not be seen. Hence, respondents were deprived of the personal visual benefits they accrue from bird-feeding, but the birds would still benefit from being fed. A positive valuation of birds 'fed but not seen' might be interpreted as revealing cross-species altruism in the form of a willingness to pay for increases in the welfare of birds, or to gain a 'warm glow' from personal actions which contribute towards this end. Consistent with the concept of nature connectivity, individuals might feel special concern for the welfare of the particular birds that visit their gardens and 
that depended on the food dispensed there, even if those birds were not actually seen. Alternatively (or additionally), such options might be interpreted as revealing a willingness to pay for the existence value of local bird populations or an option value for future encounters.

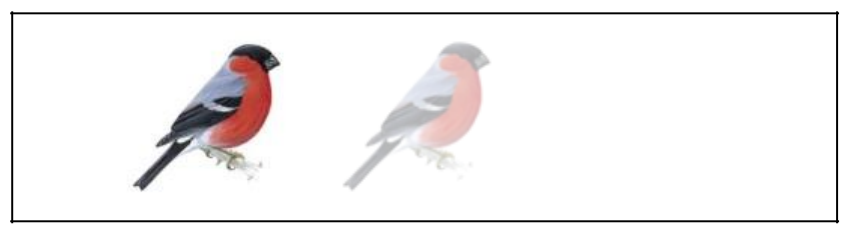

Figure 3: Representation of visibility. The bird on the left both feeds and is observed by the person dispensing the food whilst the bird on the right feeds but is not observed.

Birds that would be fed but not seen were displayed visually as faded images. Figure 3 shows how this difference was represented in the instructions. For simplicity, we restricted the number of bird species subjected to this treatment to just two - woodpigeon and bullfinch - and used only the 'one bird' frequency rating. These two species display starkly different characteristics, the former a common, pest and plain species, the latter possessing a priori positive qualities of colourfulness and rarity.

In the baseline and each feeding option, the frequency attribute for each species was chosen from one of the following four options: either no birds of that species would come to the garden ('none'), or one bird of that species would come and be seen ('single'), or between two and five birds of that species would come and be seen ('multiple'), or one bird of that species would feed but not be seen ('unseen'). The cases actually used in the experiment are shown in Table 1.

Table 1: Bird-attraction attributes used in baseline and feeding options

\begin{tabular}{|c|c|c|c|c|}
\hline & $\begin{array}{c}\text { No birds } \\
\text { ('none') }\end{array}$ & $\begin{array}{c}1 \text { bird seen } \\
\text { ('single') }\end{array}$ & $\begin{array}{c}2-5 \text { birds seen } \\
\text { ('multiple') }\end{array}$ & $\begin{array}{c}1 \text { bird fed but not seen } \\
\text { ('unseen') }\end{array}$ \\
\hline Blackbird & - & B & F & - \\
\hline Bullfinch & B & F & - & F \\
\hline Woodpigeon & B & F & - & - \\
\hline Robin & B & F & - & - \\
\hline Sparrow & - & B & F & - \\
\hline Blue tit & B & F & F & F \\
\hline
\end{tabular}

Key: ' $\mathrm{B}$ ' denotes baseline case; ' $\mathrm{F}$ ' denotes case used only in feeding options; '-' denotes case not used. 
To collect further evidence about individuals' motivations for feeding birds, we included a nutrition attribute. Each option contained a 'nutritional star rating' of the bird food, ranging from basic nutrition (one star) up to very nutritious (three star) levels. As with the 'fed but not seen' birds, one possible explanation for a respondent attaching a positive valuation to the nutritional content is that this reveals cross-species altruism or a willingness to contribute to the public good of maintaining local bird populations. It is also possible that respondents believed that more nutritious food would make birds more likely to return, and so be seen on later occasions. While private and public motivations are not mutually exclusive, a respondent's willingness to trade-off nutritional quality against other desirable properties would be suggestive of motivations that are not linked to the private enjoyment from directly watching birds feed. Nutritional content is particularly useful in relation to our external validity test, because the nutritional content of commercial bird food products is a salient dimension in marketing and product differentiation. Respondents who feed garden birds are therefore likely to be aware of this attribute. Information about the nutritional content and prices of bird food products can be used to check the credibility of responses to the choice experiment.

Including a price or cost attribute is essential as it allows for a trade-off between desirable attributes and the consumption of other goods, thereby enabling the computation of willingness-to-pay measures. A recurring problem in wildlife valuation studies is that creatures can rarely be presented as a marketed good, making it difficult to find a credible payment vehicle. Many studies use either charitable donations or taxation as the method by which respondents should assume they will pay, but neither of these mechanisms easily captures both the idea that the respondent's payment is the result of a voluntary choice and that the respondent cannot enjoy the environmental benefit unless she pays for it. The latter is relevant in the context of bird watching since sustaining the bird population is a local public good but the degree to which an individual derives use values from it depends among other things on her contribution in the form of food provision. Taxation is naturally understood as non-voluntary, and the mention of taxes is liable to cue thoughts about the fairness or unfairness of the tax system and the efficiency or inefficiency with which tax revenue is spent (Rosen \& Small, 1979). Even in revealed preference contexts, adjustments 
of tax payments can fail to reliably elicit the WTP for public goods (Diederich and Goeschl, 2013). Charitable contributions do not tie benefits to payments and hence don't capture an important dimension of the relevant setting. By using expenditure on the purchase of bird food as the payment vehicle, we avoid these problems. It is easy for respondents to understand that purchase decisions are voluntary and that those decisions will determine the characteristics of the birds that visit their gardens. As noted in the introduction, the use of this attribute ensures that a substantial share of participants have experience using it. Market experience has been shown to substantially reduce 'anomalies' such as the endowment effect (List, 2003). Moreover, using a payment vehicle that is a private good facilitates external validity tests. The price attribute took values in the range from $f 0.99$ to $£ 4.99$ per $1 \mathrm{~kg}$ bag of bird food, in intervals of $£ 0.50$. These values are in line with the range of current market prices. Respondents were told that a $1 \mathrm{~kg}$ bag could be expected to supply food for 20 feeding episodes.

The final attribute was the donation. Respondents were informed that the price of some options included a contribution to a wildlife charity. This would seek to restore wetland habitats in East Anglia, the region where the experiment was conducted, with the aim of increasing bittern populations. The bittern is a bird species regionally recognised as a flagship species for conservation and tourism. Furthermore, respondents were reminded that the bittern is a rare and elusive species, meaning that their contribution would be unlikely to reward them with a greater chance of actually seeing bitterns in the future. This attribute was used to elicit a more conventional type of existence value for wildlife. By eliciting this valuation alongside valuations of interactions with everyday wildlife, we hoped to gain some insights into the value that people derive from everyday wildlife relative to that derived from rare and iconic species. In each feeding option, the donation attribute took a value of zero (no donation), $£ 0.50, £ 1.00$ and $£ 1.50$. 


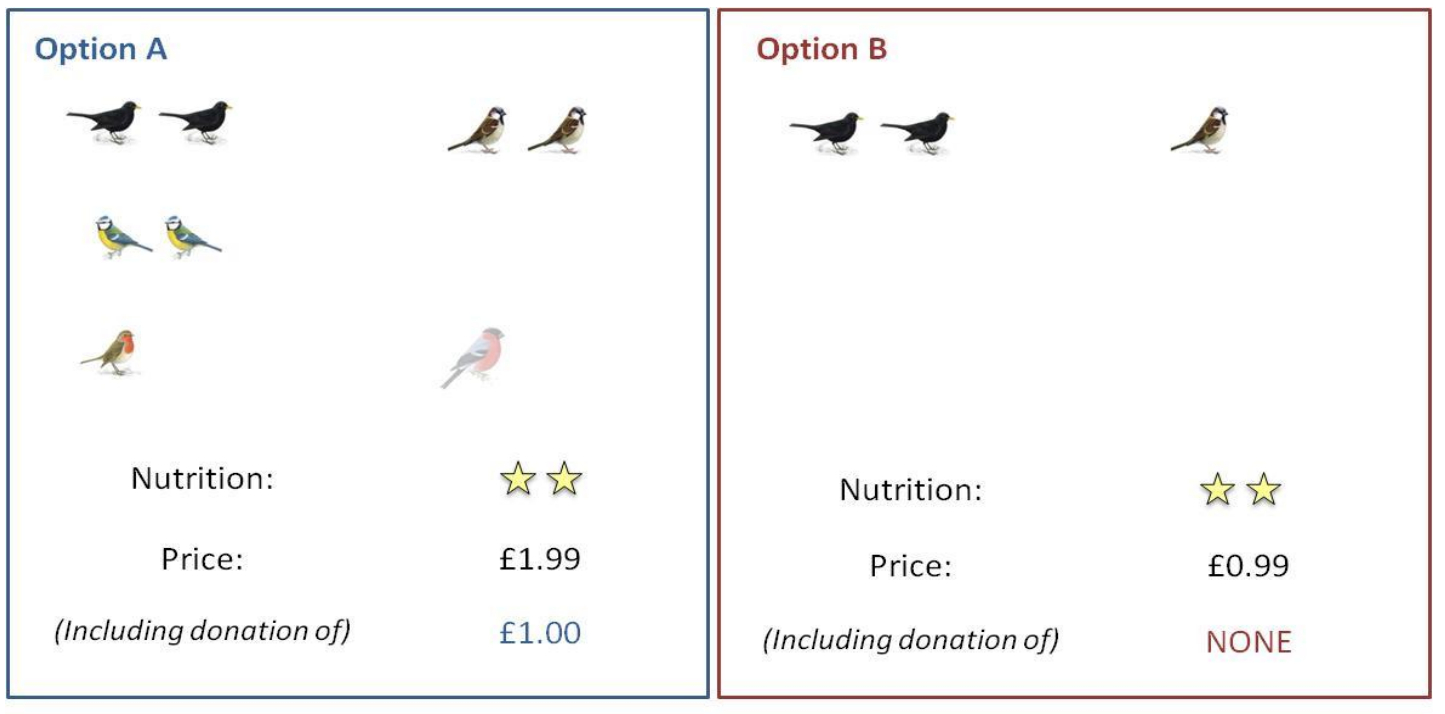

Option C : Buy Neither

Choice 7
Please indicate your preferences on Page 1 of the Answer Sheet by placing a 1 in the box of your top choice and a 2 in that of your second choice

Figure 4: A sample choice set

\subsection{The choice experiment: implementation}

Each respondent faced sixteen choice sets. The number of tasks is towards the upper end of the usual range for choice experiments (Swait \& Adamowicz, 1996; Adamowicz et al, 1998; Scheufele \& Bennett, 2012) but, given the familiarity of the topic, we judged that respondents would find it manageable. This was confirmed by pilot testing, where focusgroup participants gave no indication that the duration or complexity of the choice task had created instances of fatigue or other potentially undesirable response patterns.

Figure 4 shows a typical choice set. Tasks were displayed on a laptop screen, meaning each choice set was presented at a size approximately equivalent to 'A4 landscape' dimensions. Each presented two bird feeding options and a constant baseline option of not feeding. Presenting sets with three alternatives has been found to improve model robustness (Rolfe \& Bennett, 2009). Each respondent was asked to state their first and second preferences among the three options in each choice set, effectively providing a complete ranking of 
those options. A description of the baseline was given at the instructions stage, and a copy was available on the respondent's desk for them to review if necessary.

The experiment was conducted as a series of face-to-face interviews, each involving a researcher and a single participant. Participants were randomly selected and asked if they would like to take part in a survey which explored people's attitudes to bird-feeding. Tutorial-style instructions (provided as supplementary material) and tasks were presented on computer screens, but the researcher read the instructions aloud to subjects and answered any questions about them, overcoming issues of illiteracy or ambiguity. A laminated copy of the tutorial (provided in Appendix B) was also available for later reference if required.

Surveys were conducted at a Norwich garden centre in mid-July 2012. At such a location, it was reasonable to assume that respondents would be interested in garden-related issues and therefore well positioned to participate in the experiment. A garden centre location also ensured a non-obligatory and relatively leisured environment in which potential respondents were likely to have time to participate in a survey but could decline if they so chose. We recognise that garden centre customers are not a representative sample of the population. By collecting socio-demographic data (see Section 2.3) we were able to assess the representativeness of our sample with respect to gender, age and income. In interpreting our results, it is necessary to keep in mind that, relative to the general population, garden centre customers are likely to have higher valuations of any activity, including bird-feeding, that takes place in gardens. However, if one is primarily interested in people's motivations for engagement with everyday wildlife (rather than in the statistical frequency of this activity), it makes sense to use a sampling frame that is skewed towards population groups that are particularly likely to take part in the type of engagement that is being investigated.

\subsection{The bird identification quiz}

This part of the survey tested respondents' knowledge of garden birds. Each respondent was shown pictures of the six species shown in Figure 1, labelled ' $A$ ' to ' $F$ ', and was asked to 
try to match the letters to the correct bird names from a list of 16 possible options. One purpose of collecting information about respondents' knowledge about birds was to investigate whether any relationship existed between knowledge and valuation. Previous studies have suggested that knowledge is a key determinant of value (e.g. Metrick \& Weitzman, 1996), but this has not been in the context of everyday wildlife. Intuitively, one would expect the existence value placed on a relatively rare species to be influenced positively by knowledge about it, but it is not self-evident that this effect would extend to everyday interactions with nature where concrete experiences rather than abstract knowledge are likely to be more important. The quiz also allowed a partial test of participants' understanding of the pictures used to represent bird species in the choice experiment. If participants can correctly match commonly-used species names such as 'robin' and 'blackbird' with the corresponding pictures, and if those species are in fact commonly encountered, it is reasonable to infer that participants could connect the pictures with their experiences of those encounters.

\subsection{The socio-demographic and behavioural questionnaire}

This component of the survey was a standard tick-box questionnaire. The behavioural section of the questionnaire, described as a 'respondent survey', asked about the type and regularity of feeding that respondents undertook, and whether they contributed to environmental charities. It also elicited their bird-feeding motivations, asking them to rate a range of plausible reasons for engaging in the action on a 1 - 5 Likert scale. Sociodemographic questions established each respondent's gender, age and post-tax household income. Respondents were assured these data would remain both anonymous and compliant with data protection laws.

\section{The empirical model}

The data is analysed using a conditional logit model. Algebraically, this means that the utility person $n$ derives from alternative $j$ is assumed to take the form characterised by, 


$$
U_{n j}=\beta^{\prime} x_{n j}+\varepsilon_{n j}
$$

Here, the vector $x_{n j}$ contains the characteristics of a given option in the choice experiment. The parameter $\beta$ relates this to the preferences over the attributes at these particular levels. We assume that $\varepsilon_{n j}$ follows a Gumbel distribution, which is deemed appropriate when included as an additive element to the utility function (McFadden, 1974; Louviere et al, 2000; Hoyos, 2010). The projected probability for the average participant to choose option $i$ given the choice set $J$ can be computed as follows:

$$
\operatorname{Prob}(i)=\int\left(\frac{\exp ^{\beta^{\prime} x_{n i}}}{\sum_{j} \exp p^{\beta^{\prime} x_{n j}}}\right) f(\beta) d \beta .
$$

Attribute coefficients thus represent the respondent's change in probability for choosing an option if, ceteris paribus, there is a unit change in that attribute's level when described as a discrete variable, or through its presence relative to a base case for dummy (0-1) coded attributes (Bennett \& Blamey, 2001). The coefficient on price $\left(\beta_{\text {price }}\right)$ represents the marginal utility of income, which is assumed to remain constant and is expected to be negative (Hanley et al, 1998a). Presuming that product characteristics act as normal goods, determining any attribute's marginal valuation then involves taking the ratio of its coefficient against that of price (Hoyos, 2010).

$$
W T P_{x}=\frac{-\beta_{x}}{\beta_{\text {price }}}
$$

We cluster over individuals to take into account that their decisions across different choice sets are not independent. To check for robustness we repeat the regression on the preferred sample with a mixed-logit regression that allows for random taste variation between participants.

\section{Results}

200 respondents completed all three parts of the survey. At approximately 50\%, the response rate was good and stated reasons for decline typically related to time constraints rather than lack of understanding or lack of interest. 119 (59.5\%) of respondents were female. 
We aimed at surveying individuals who were responsible both for looking after a garden area and for household budgeting. Consequently much of the UK's younger population were not prime survey candidates. Table 2 decomposes the age profile of our sample, and compares this to Norfolk population data as derived from the 2011 Census (Norfolk Insights 2013). There is a significant difference between the two groups $(z=4.015, p(z)=0.0001)$ which is driven by under-representation of lower age brackets (particularly those aged 2645 ) and an excess of respondents aged above 56. Considering our sample specification described above, this age profile does not inhibit the transferability of our results to a wider (albeit adjusted) target population.

\begin{tabular}{ccc}
\hline Age bracket & Sample population (\%) & Norfolk population (\%) \\
\hline $\mathbf{1 8 - 2 5}$ years & 5.5 & 7.6 \\
$\mathbf{2 6 - 3 5}$ years & 7.5 & 14.1 \\
$\mathbf{3 6 - 4 5}$ years & 5.5 & 15.4 \\
$\mathbf{4 6 - 5 5}$ years & 21.0 & 17.3 \\
$\mathbf{5 6}-\mathbf{6 5}$ years & 23.0 & 16.7 \\
Over 65 years & 37.5 & 28.7 \\
\hline
\end{tabular}

Table 2: Age profile comparison

Table 3 provides the income profile of the sample. $12 \%$ of respondents chose not to share this information. The income distribution in our sample is broadly representative of that in the general Norfolk population $(z=0.823, p(z)=0.4108$; data from Norfolk County Council, 2013). The slight under-representation of the lowest income brackets may reflect the aforementioned under-representation of young individuals.

\begin{tabular}{|c|c|c|}
\hline Income bracket & $\begin{array}{l}\text { Sample population (\%) } \\
\text { conditional on disclosure }\end{array}$ & $\begin{array}{c}\text { Norfolk } \\
\text { population (\%)* }\end{array}$ \\
\hline Under $£ 20,000$ & 31.2 & 39 \\
\hline$£ 20,000-£ 29,999$ & 27.2 & 21 \\
\hline$£ 30,000-£ 39,999$ & 14.1 & \multirow[t]{3}{*}{24} \\
\hline$£ 40,000-£ 49,999$ & 10.2 & \\
\hline$£ 50,000-£ 59,999$ & 5.1 & \\
\hline$£ 60,000-£ 69,999$ & 3.9 & \multirow{4}{*}{16} \\
\hline$£ 70,000-£ 79,999$ & 1.6 & \\
\hline$£ 80,000-£ 89,999$ & 1.1 & \\
\hline Above $₫ 90,000$ & 5.6 & \\
\hline Response rate & $88 \%(176 / 200)$ & $\mathrm{N} / \mathrm{A}$ \\
\hline
\end{tabular}

Table 3: Income profile comparison

*Data approximations from Norfolk Insight (CACI), 2010 
It is useful to begin by summarising the results of the bird identification quiz, as these assist the interpretation of our main results. The robin and blackbird (both correctly identified by 99.0\% of respondents) proved to be the most easily identified species, followed by the blue tit (89.5\%) and wood pigeon (84.5\%). The house sparrow was the least frequently identified species (52\%), but an additional $12.0 \%$ of respondents misidentified it as the very closely related tree sparrow. The relatively rare bullfinch was correctly identified by $55.5 \%$ of respondents. These results show that most participants had a good knowledge of local birds, and provide reassurance that they were generally able to understand what the pictures represented. However, $23.5 \%$ of respondents misidentified the bullfinch as the somewhat similar but much more common chaffinch. (15.5\% of respondents were unable to give it any name.) The implication is that a significant minority of participants linked the bullfinch picture with their actual experiences of an objectively common bird. When drawing inferences about the value of rarity, we therefore give special attention to the subsample of participants who correctly identified all six birds.

We now turn to the choice experiment itself. The variables capturing the different attribute levels described above are summarized in Table 4. The number and visibility of bird species are captured by a dummy variable for each attribute level and species. Nutrition, donation and the cost of the bird food (price) are included as well as one interaction variable between nutrition and the total number of birds irrespective of species (and visibility) visiting a garden in a given option.

\begin{tabular}{llll} 
Variable name & Type & Definition & Baseline \\
\hline blackbird_multiple & dummy & 1 if $2-5$ blackbirds seen \& fed, 0 otherwise & 1 blackbird seen \& fed \\
bullfinch_single & dummy & 1 if 1 bullfinch fed but not seen, 0 otherwise & no bullfinch seen \& fed \\
bullfinch_unseen & dummy & 1 if 1 bullfinch fed but not seen, 0 otherwise & no bullfinch seen \& fed \\
pigeon_single & dummy & 1 if 1 wood pigeon seen $\&$ fed, 0 otherwise & no pigeon seen \& fed \\
pigeon_unseen & dummy & 1 if 1 wood pigeon fed but not seen, 0 otherwise & no pigeon seen \& fed \\
robin_single & dummy & 1 if 1 robin seen \& fed, 0 otherwise & no robin seen \& fed \\
sparrow_multiple & dummy & 1 if $2-5$ sparrows seen \& fed, 0 otherwise & 1 sparrow seen \& fed \\
tit_single & dummy & 1 if at least 1 blue tit seen \& fed, 0 otherwise & no blue tit seen \& fed \\
tit_multiple & dummy & 1 if $2-5$ blue tits seen \& fed, 0 otherwise & 1 blue tit seen \& fed \\
nutrition & continuous & takes values $1,2,3$ according to 'star rating' of food & \\
price & continuous & price of food bag in $f$ & \\
donation & continuous & amount donated to wildlife charity in $₹$ (included in price) & \\
nutnum & continuous & nutrition * total number of birds fed &
\end{tabular}

Table 4: Definitions of variables used in regression analysis

Regression results for several (sub-)samples are presented in Table 5. The corresponding valuations of bird species are given in Table 6. Regression (1) estimates the values for the 
complete sample. Regressions (2) to (6) use the same explanatory variables but on a subgroup of respondents who hold particular or distinct characteristics. Regression (7) presents results from a mixed-logit model for the same sample used in Regression (2). Regression (2) includes only participants that have experience both with the good (they report feeding birds at least occasionally) and the payment vehicle (they purchase bird food). Regression (3) studies inexperienced participants. They either do not feed birds $(n=38)$ or do so but never buy bird food ( $n=9)$. Results for non-feeders only are not reported but look very much the same. Regression (4) isolates those who correctly named all six of the species in the bird identification quiz, regardless of whether or not they have experience with bird feeding or feed purchases while Regression (5) has the same requirement in terms of knowledge but only includes experienced participants. Finally, Regression (6) shows the values for experienced participants who also scored highly on benefactor attitudes, that is motivations for bird-feeding which describe that activity in terms of benefits to birds, rather than benefits to themselves. Respondents whose aggregated Likert score for the $2^{\text {nd }}, 3^{\text {rd }}$ and $4^{\text {th }}$ motives in question 5 of the 'respondent survey' (see Appendix D) exceeded 12 of a possible 15 are considered benefactors for this purpose. 


\begin{tabular}{|c|c|c|c|c|c|c|c|}
\hline \multirow[b]{2}{*}{ Sample } & \multicolumn{6}{|c|}{ Conditional Logit } & \multirow{2}{*}{$\begin{array}{l}\text { Mixed Logit } \\
\text { Experience }\end{array}$} \\
\hline & Full sample & Experience & No Exp. & Knowledge & Know. \& Exp. & Benefs. \& Exp. & \\
\hline Regression & 1 & 2 & 3 & 4 & 5 & 6 & 7 \\
\hline \multirow[t]{2}{*}{ blackbird_multiple } & $0.398 * * *$ & $0.608 * * *$ & -0.072 & $0.715^{* * *}$ & $0.877 * * *$ & $0.635 * * *$ & $0.970 * * *$ \\
\hline & $(0.000)$ & $(0.000)$ & $(0.668)$ & $(0.001)$ & $(0.001)$ & $(0.001)$ & (0.000) \\
\hline \multirow[t]{2}{*}{ sparrow_multiple } & $0.410 * * *$ & $0.564 * * *$ & -0.002 & $0.741 * * *$ & $0.808 * * *$ & $0.465 * * *$ & $0.798 * * *$ \\
\hline & $(0.000)$ & $(0.000)$ & (0.991) & $(0.000)$ & $(0.000)$ & (0.001) & (0.000) \\
\hline \multirow[t]{2}{*}{ tit_single } & $0.364 * * *$ & $0.458 * * *$ & 0.083 & $0.602 * * *$ & $0.590 * * *$ & $0.310 * * *$ & $0.462 * * *$ \\
\hline & $(0.000)$ & $(0.000)$ & (0.491) & $(0.000)$ & $(0.000)$ & (0.001) & $(0.000)$ \\
\hline \multirow[t]{2}{*}{ tit_multiple } & $1.268 * * *$ & $1.161^{* * *}$ & $0.511^{* * *}$ & $1.814 * * *$ & $1.343^{* * *}$ & $0.887 * * *$ & $2.040 * * *$ \\
\hline & $(0.000)$ & $(0.000)$ & $(0.003)$ & $(0.000)$ & $(0.000)$ & $(0.000)$ & $(0.000)$ \\
\hline \multirow[t]{2}{*}{ pigeon_single } & -0.126 & $-0.334 * *$ & 0.120 & -0.117 & -0.197 & $-0.306 *$ & -0.213 \\
\hline & $(0.182)$ & $(0.022)$ & $(0.302)$ & $(0.602)$ & $(0.516)$ & $(0.062)$ & (0.263) \\
\hline \multirow[t]{2}{*}{ pigeon_unseen } & $-0.178^{*}$ & -0.227 & -0.207 & $-0.452 * *$ & -0.387 & 0.086 & $-0.334^{*}$ \\
\hline & $(0.060)$ & $(0.107)$ & $(0.161)$ & (0.037) & $(0.170)$ & $(0.616)$ & $(0.066)$ \\
\hline \multirow[t]{2}{*}{ robin_single } & $0.667^{* * *}$ & $0.850 * * *$ & $0.448 * * *$ & $1.083 * * *$ & $1.316 * * *$ & $0.734 * * *$ & $1.618^{* * *}$ \\
\hline & $(0.000)$ & $(0.000)$ & (0.006) & $(0.000)$ & $(0.000)$ & $(0.000)$ & (0.000) \\
\hline \multirow[t]{2}{*}{ bullfinch_single } & $0.504 * * *$ & $0.672 * * *$ & $0.274 *$ & $0.404^{* *}$ & $0.455^{* *}$ & $0.644 * * *$ & $0.799 * * *$ \\
\hline & $(0.000)$ & $(0.000)$ & $(0.053)$ & $(0.018)$ & $(0.031)$ & (0.000) & $(0.000)$ \\
\hline \multirow[t]{2}{*}{ bullfinch_unseen } & $0.404^{* * *}$ & $0.345^{* *}$ & $0.492^{* *}$ & $0.524^{* *}$ & 0.352 & -0.030 & $0.520 * *$ \\
\hline & $(0.000)$ & $(0.014)$ & $(0.010)$ & (0.031) & (0.229) & $(0.860)$ & $(0.021)$ \\
\hline \multirow[t]{2}{*}{ nutrition } & $0.575^{* * *}$ & $0.734 * * *$ & 0.161 & $0.612 * * *$ & $0.580 * * *$ & $0.763 * * *$ & $1.570 * * *$ \\
\hline & $(0.000)$ & $(0.000)$ & $(0.336)$ & $(0.000)$ & $(0.002)$ & $(0.000)$ & $(0.000)$ \\
\hline \multirow[t]{2}{*}{ donation } & $-0.002 * *$ & $-0.002 * *$ & -0.002 & $-0.003 * *$ & -0.002 & -0.001 & $-0.002 *$ \\
\hline & $(0.013)$ & (0.049) & $(0.184)$ & $(0.046)$ & & & (0.069) \\
\hline \multirow[t]{2}{*}{ nutnum } & $-0.055^{* * *}$ & $-0.071 * * *$ & -0.009 & $-0.076 * * *$ & $-0.075^{* * *}$ & $-0.050 * *$ & $-0.105^{* * *}$ \\
\hline & $(0.000)$ & $(0.000)$ & $(0.711)$ & $(0.001)$ & $(0.007)$ & (0.020) & (0.000) \\
\hline \multirow[t]{2}{*}{ price } & $-0.001 * * *$ & $-0.001 * *$ & $-0.002 * * *$ & $-0.001 * *$ & -0.001 & 0.001 & $-0.002 * *$ \\
\hline & $(0.000)$ & (0.026) & $(0.000)$ & (0.048) & (0.119) & (0.192) & (0.013) \\
\hline Model Fit $\left(\chi^{2}\right)$ & 202.53 & 221.01 & 61.93 & 158.91 & 197.45 & 139.33 & 1127.04 \\
\hline Pseudo $\mathrm{R}^{2}$ & 0.1777 & 0.2817 & 0.0278 & 0.2647 & 0.3122 & 0.3078 & \\
\hline Observations & 16000 & 12154 & 3836 & 5040 & 4396 & 7436 & 12154 \\
\hline \# of participants & 200 & 152 & 48 & 63 & 55 & 93 & 152 \\
\hline
\end{tabular}

Table 5: Estimated coefficients for Conditional / Mixed Logit Regressions on six

(sub)samples. Variable definitions can be found in Table 4. p-values in parentheses.

$* \mathrm{p}<0.10, * * \mathrm{p}<0.05, * * * \mathrm{p}<0.01$

\begin{tabular}{|l|c|c|c|c|c|c|}
\hline & $\begin{array}{c}\text { Full } \\
\text { sample }\end{array}$ & Experience & $\begin{array}{c}\text { No } \\
\text { Experience }\end{array}$ & Knowledge & $\begin{array}{c}\text { Knowledge \& } \\
\text { Experience }\end{array}$ & $\begin{array}{c}\text { Benefactor \& } \\
\text { Experience }\end{array}$ \\
\hline Regression & 1 & $\mathbf{2}$ & 3 & 4 & 5 & 6 \\
\hline blackbird_multiple & $7^{* * *}$ & $\mathbf{1 1}$ & -1 & 9 & 13 & 14 \\
\hline sparrow_multiple & $7^{* * *}$ & $\mathbf{1 1}$ & 0 & 10 & 12 & 10 \\
\hline tit_single & $15^{* * *}$ & $\mathbf{2 1}$ & 2 & 20 & 22 & 17 \\
\hline tit_multiple & $15^{* * *}$ & $\mathbf{2 2}$ & $5^{* *}$ & 16 & 20 & 20 \\
\hline pigeon_single & -5 & $\mathbf{- 1 6}$ & 3 & -4 & -7 & -17 \\
\hline pigeon_unseen & -7 & $\mathbf{- 1 1}$ & -5 & -15 & -14 & 5 \\
\hline robin_single & $27^{* * *}$ & $\mathbf{4 0}$ & $11^{*}$ & 36 & 48 & 41 \\
\hline bullfinch_single & $21^{* * *}$ & $\mathbf{3 1}$ & $7^{* *}$ & 14 & 17 & 36 \\
\hline bullfinch_unseen & $16^{* *}$ & $\mathbf{1 6}$ & $12^{* *}$ & 18 & 13 & -2 \\
\hline \# of participants & 200 & $\mathbf{1 5 2}$ & 48 & 63 & 55 & 93 \\
\hline
\end{tabular}

Table 6: Estimated WTP for an additional feeding visit of bird species in 2012 pence Sterling.

$* \mathrm{p}<0.10, * * \mathrm{p}<0.05, * * * \mathrm{p}<0.01$ based on bootstrap with 1,000 replications 
For each regression, the monetary valuations presented in Table 6 refer to an additional bird visiting for a feed expressed in British pence (where 1 pence (1p) is equivalent to $£ 0.01$ or $€ 0.014)$. This is implied by the estimation results of Table 5. For blackbirds, sparrows and tits the highest frequency attribute (ending with multiple) was 2-5 birds. The values presented in Table 6 represent the WTP for a single additional bird based on the assumption that on average 2.5 additional birds are seen and that marginal utility for each additional bird remains constant. ${ }^{4}$ This is derived by assuming that there is an equal chance that, as described by the frequency key, "2-5 birds" would create 1, 2, 3 or 4 more birds relative to the 'single bird' case. Thus dividing the increment by 2.5 takes an average of these possible events.

In contrast to the bird species coefficients in Table 5, most of the WTPs presented in Table 6 are not statistically different from zero. This is driven by the high standard errors of the price coefficient for subsamples 2 and 4 to 6 . The price coefficient itself does not differ significantly between samples, except for inexperienced participants who have a significantly higher (5\%-level) marginal value of income. The lack of significance of the WTP estimates for these samples is hence not driven by participants' indifference towards birds, but rather by their disagreement about how much to care about money (relative to birds). We will therefore mainly focus on the revealed preference order for different bird species that can be deduced from comparing coefficients in Table 5 rather than on differences in WTP.

The preferred regression is the one on experienced participants (2). There are two reasons for this. First, the existing literature clearly indicates that stated preference methods are most reliable when people are familiar with both the good to be evaluated and the payment vehicle used. This is clearly the case for those participants feeding birds with purchased bird food. Second, this subsample is most comparable to the hedonic pricing analysis of bird food sales data we conduct later, as the latter only includes people participating in the market for bird food.

\footnotetext{
${ }^{4}$ The latter can be justified by looking at the results for tits which is the only species for which no, one or multiple individuals could be observed in the choice set. In Table 5, Regression (2) the coefficient to observe multiple rather than one tit is 1.161 . Dividing this by 2.5 yields 0.464 which is very close to the coefficient of tit_single (0.458) and well within its 95\%-confidence interval [0.309; 0.607].
} 
In relation to birds that are both fed and seen, experienced participants have a clear ranking of the species: robin and bullfinch $\succ$ blue tit $\succ$ sparrow and blackbird $\succ$ woodpigeon. ${ }^{5}$ Apart from the woodpigeon, which has a negative value, all species are valued positively. This ranking is consistent with the prior intuition that people value aspects such as colour or associated aesthetics when interacting with wildlife. The literature on subjective well-being provides additional clues about the attractiveness of the robin and the blue tit as feeding visitors to gardens. If bird-feeding expresses a warden motivation, one might expect the highest valuations for those species which provide humans with the greatest opportunities to exhibit emotions of responsibility and interconnectedness in repeated interactions. The size, stature and feeding habits of robins and blue tits are classic characteristics that humans, consciously or unconsciously, interpret as signals of dependency (Tinbergen, 1953). By being common birds, and thus frequent visitors to gardens, they offer opportunities for repeated and routine interaction which then boosts the satisfaction that humans derive from feeding them.

In contrast, there is no indication that rarity is valued. There is no obvious relationship between the ranking of the six species by value and their relative frequency in the local area (given in Appendix A). Despite being much rarer than the similarly colourful robin, the bullfinch attracted a lower valuation ${ }^{6}$ than the robin from experienced participants. Since, as noted above, some participants misidentified the picture of the bullfinch as representing a more common bird, it is useful to consider the valuations of the subset of experienced participants who correctly identified all six species (Regression (5)). In this subsample, too, the bullfinch is ranked below the robin. In fact, the valuation difference is much greater than for experienced participants as a whole, and is strongly significant $(p=0.0065)$. Of course, relative rarity is not the only dimension of difference between the robin and the bullfinch; the robin has other characteristics, such as territoriality and its 'tameness' in interacting with humans, which might make it particularly attractive to people with warden attitudes. Our results do not allow us to conclude that experienced feeders of birds attach no value to rarity. But they give some support to the conjecture that the satisfaction of seeing relatively

\footnotetext{
${ }^{5}$ This refers to their willingness to substitute one bird species for another. Results (p-values) of chi squared tests: robin_single vs. bullfinch_single 0.31, robin_single vs. tit_single 0.004, bullfinch vs. tit_single 0.092, tit_multiple vs. blackbird_multiple 0.001 , tit_multiple vs. sparrow_multiple 0.000 . woodpigeon_single is significantly negative while all other species coefficients are significantly positive in Regression (2).

${ }^{6}$ Note that in regression (2) the difference in the coefficients is not significant.
} 
rare species is not a major motivation for engagement with garden birds. We summarize the above findings as:

\section{Result 1}

Participants who have experience (here: past feeding activity and purchases of bird food) with common garden birds attach positive value to engagement with all bird species, with the exception of a negatively-valued 'pest' species. Species rankings follow common judgments of aesthetics. There is no evidence that rarity is valued.

The subsample that has no experience with bird feeding and purchasing bird food ${ }^{7}$ presented in Regression (3) clearly has lower valuation coefficients than the experienced subsample for all the species that are valued positively by the latter. For all these species, this difference is significant at the $1 \%$ level. Only for the birds that are fed but not seen, i.e. where the interaction does not involve any real experience, is the difference between experienced and inexperienced participants not significantly different. Inexperienced participants attach significantly positive values only to the robin, bullfinch and multiple blue tits. There is a rough parallel here with experienced participants' preferences for colourful birds, but there is no evidence that inexperienced participants value the other species or distinguish between them. These differences between experienced and inexperienced respondents may reflect causal effects of experience. Alternatively, they may be due to selfselection: other things being equal, people who have relatively low valuations for engagement with wildlife, and/or relatively little interest in its properties, are less likely to have previously chosen to feed birds.

\section{Result 2}

Relative to experienced participants, inexperienced participants attach lower value to engagement with birds and discriminate less finely between bird species.

\footnotetext{
${ }^{7}$ Results (not presented) for the subsample focusing on participants that never feed birds $(\mathrm{N}=39)$ look very similar to those in Regression (3).
} 
We now consider the extent to which participants acts as benefactors towards birds, i.e. care for them over and above what is necessary to be able to watch them feeding. The choice experiment contained three attributes that test for their presence: birds that can be fed but not seen, the nutritional content of the bird food and a donation to a wildlife charity. In addition to that, the behavioural questionnaire explicitly asked what motivates participants to feed birds.

The nutrition coefficient has a consistently high and positive value across samples except for inexperienced participants. Providing "a greater level of nutrition to each bird which is fed" (quote from instructions) can be expected to increase their fitness and thereby somewhat dependent on the season - increase their own or their offspring's chances of survival or reduce the effort spent on foraging. The stated preference for more nutritious options can hence be interpreted as being motivated by concern about either the individual bird's wellbeing or the local bird population. Whether this in turn is driven by hopes to induce more bird visits and hence direct consumption benefits in the future cannot be identified in the current set-up.

The regressor nutnum describes the interaction between the total number of birds present on a given alternative and the nutritional rating of that option. The coefficient is negative and significant across all samples except those without experience, suggesting that the importance of nutrition declines when more birds are attracted and fed by a particular option. Further analysis (not presented here) found that the number of birds fed per se (i.e. irrespective of species) plays no significant role in people's choice-preference. Given that the coefficients for nutrition are positive and highly significant, the implication is that respondents attach higher value to the nutritional characteristics of bird food if that food is eaten by fewer rather than more birds.

This pattern of valuation might imply an increased sense of responsibility to care for an individual bird in what humans perceive as a more "intimate" relationship. This assertion is 
consistent with the findings of Jones (2011), who reviews several studies which show that feeders express feelings of attachment and protection and a desire to care for 'their' birds.

The results from the 'fed but not seen' bird attribute points in a similar direction. In Regressions (1) - (4) there is a significant positive preference to feed a bullfinch that cannot be observed. The change in the propensity to switch to an option with a bullfinch fed but not seen in Regression (2) is about half that of a bullfinch that can be observed. This difference is significant at the $5 \%$-level. Hence, when being deprived of any direct and immediate consumption value participants still contribute, but less than when those consumption benefits are present. Again, this might be driven by expectations about future own consumption concern about the birds' welfare or population levels more generally. The findings for the 'fed but not seen' woodpigeon are less clear cut. While the willingness-topay among experienced participants (Regression 2) is between zero and the (negative) WTP for feeding and watching a woodpigeon, the preference ranking is not statistically significantly different from either of them. Moreover, this is far from consistent across samples. Somewhat surprisingly, the subsample that focuses on experienced participants that report high scores on the benefactor feeding motives in the questionnaire (Regression 6), features effectively a zero valuation for birds 'fed but not seen', regardless of whether it's a bullfinch or a woodpigeon. At the same time, the group of experienced and (selfdeclared) benefactors towards bird clearly values extra nutrition $(p=0.000)$ and at about the same level as the sample in Regression (2).

\section{Result 3}

Participants are willing to contribute to the fitness of local birds even if they have no immediate (additional) consumption benefit from doing so. The willingness to purchase fitness by means of more nutritious food is decreasing in the number of birds fed indicating that concern for the individual bird rises when there are fewer of them.

Some further insights can be gained from looking at the answers to question 5 of the exit questionnaire which asked participants to rate their reasons for feeding birds on a scale of 1 
('not important to me') to 5 ('very important to me'). Table 7 shows the average rating attached to each reason for the full sample, for all experienced participants and for the subgroup that state a benefactor attitude (measured based on responses to this very question). The ranking is the same for all three samples. ${ }^{8}$ The reason with the highest rating is 'enjoyment from watching them', followed by 'help towards bird populations' and 'I feel they need the extra food'. The motive with the highest rating refers to the private enjoyment gained through engaging with wildlife, rather than to concern for the wildlife itself (whether expressed in terms of the welfare needs of individual birds or, more ecologically, in terms of maintaining bird populations). It is also interesting that 'It makes me feel good to think that I am helping' had a lower average rating than reasons which expressed direct concern for the welfare of birds. This perhaps suggests, contrary to the implications of the 'warm glow' hypothesis (Andreoni, 1990), that individuals can be motivated to meet other creatures' needs without thinking that they receive any benefit from doing so.

\begin{tabular}{cccc}
\hline \multicolumn{1}{c}{ Reason } & \multicolumn{2}{c}{ Average rating } \\
\hline & Full sample & Experienced & Benefactor \& Exp. \\
\hline Enjoyment from looking at them & 4.39 & 4.75 & 4.83 \\
Help towards bird populations & 4.18 & 4.55 & 4.79 \\
I feel they need the extra food & 3.97 & 4.36 & 4.65 \\
It makes me feel good to think I am helping & 3.55 & 3.91 & 4.45 \\
Throwing leftover food in the bin is a waste & 2.90 & 2.99 & 3.10 \\
\hline
\end{tabular}

Table 7: Stated reasons for feeding birds

On average, increasing the donation to protect a regionally prominent and endangered species (the bittern) associated with an option, ceteris paribus, i.e. keeping the total price, nutrition and bird frequencies fixed, significantly reduces the attractiveness of that option in Regressions (1) and (2). Whilst at first this might appear surprising, this trend was reinforced by anecdotal discussions with respondents who claimed a distaste to engage in such compulsory philanthropy. However, this effect disappears in Regressions (3) - (6). One might interpret this response as analogous with the well-known reluctance of survey

\footnotetext{
${ }^{8}$ For the first two samples the differences between motives is significant at the $0.1 \%$-level for all pairwise comparisons. For experienced \& benefactor participants only the two highest ranked reasons are not significantly different from each other. The differences between samples are highly significant as well, with the following exceptions: the score for 'enjoyment from looking at them' for the two experienced samples is not different, as would be expected, and the scores for the food waste motive are not different across samples.
} 
respondents to report their valuations for environmental benefits when the payment vehicle is taxation (discussed in Section 2.1 above). One factor might have been that the hypothetical 'donations' in our experiment were not matched by any contributions by the bird-food producer or retailer, as is common in commercial practice and other experiments. This may have reinforced the perception that the seller of the bird-food was presuming on the good nature of the buyer. But even so, the negative donation coefficient suggests that respondents did not readily associate the idea of feeding garden birds with that of conserving endangered bird species. The more closely aligned these activities are perceived to be, the more likely it is that thinking about buying bird food will prompt positive attitudes towards bird conservation, and the less presumptuous it is for the bird-food seller to assume that buyers want to contribute to that cause. This is supported by additional results (not reported) showing that the donation coefficient becomes insignificant for experienced participants who have contributed to an environmental charity at least once over the last 12 months.

\section{Result 4}

There is no evidence that feeding garden birds is associated with an increased willingness to contribute to the protection of an endangered bird species in the region. On the contrary, when linked to the purchase of bird seed, it tends to put participants off.

This suggests that motivations for feeding garden birds may differ from those that make people willing to contribute to wildlife conservation. This difference might reflect the role of nature connectivity in bird-feeding. People are not only unlikely, but are actively discouraged from trying, to 'connect' with endangered species like the bittern. Therefore, the utility which humans can gain from the conservation of such species cannot fulfil feelings of dependency-affiliation or repeated interaction.

The results of the choice experiment provide evidence that, at least within the segment of the UK population that engages in gardening, interaction with everyday wildlife provides benefits for which people are willing to pay small amounts of money. More specifically, 
individuals attach value to being able to see common birds in their gardens. They are also willing to pay to feed birds that visit their gardens even if those birds are not seen given they belong to a desirable species, and to ensure that the food they dispense does not simply attract birds but is also nutritious. The importance of engagement, the sense of responsibility to feed birds even when this cannot be observed and many of the other aspects touched upon by the above results suggest that respondents' attitudes to bird feeding were warden-like.

\section{Section 5: A hedonic analysis of seed purchase data}

One of the severe drawbacks of stated preference (SP) studies is the tendency of individuals to respond in ways which belie their true preferences, if they exist at all (Bateman et al. 2002, p269). As has been discussed above, we have tried to minimise this problem by using a setting, good and payment vehicle that people can have actual experience with and to focus on the subsample of experienced participants. To test the external validity of our results at least broadly we do a hedonic analysis of sales data from a UK bird-food wholesaler. This is another big advantage of our payment mechanism. It offers the opportunity to, at least in principle, compare hypothetical products with those traded on real markets. However, as it will turn out, there are several other factors that substantially limit the aspects that can be investigated in the hedonic analysis. The main ones being the difficulty of mapping individual products to specific birds attracted and the inability of market generated data to inform on some of the key objectives of the discrete choice experiment, e.g. the role of motivations etc.

We use a dataset provided by a UK bird-feed wholesaler that produces and distributes sixteen different products and provided monthly sales data for these for the period of October 2012 through to September 2013. For each of the sixteen products, the dataset contains the product's weight, price and its composition. We assume that each of the 12,918 purchases made represent a consumer choosing a product from the full range of sixteen products that differ in terms of content, size and feeding method. 
Each of the sixteen products is a 'bundle' of various bird food types. The package of each product clearly displays the list of ingredients and the feeding method etc. The product characteristics used in hedonic regressions (Table 8 ) are therefore fully available to consumers at the point of purchase. Two types of ingredients, nuts and mealworms, are omitted and hence form the reference case. Both are 'special' ingredients and are also highly correlated with other characteristics, especially mealworms with price (correlation coefficient: 0.91). The max and mean of the variance inflation factor was much smaller when using the high end ingredients as reference point compared to using a more basic ingredient like maize or sunflower seed.

\begin{tabular}{lcccc}
\multicolumn{1}{c}{ Variable } & Coefficient & 95\% Confidence Interval & $\begin{array}{c}\text { WTP } \\
\text { (per 100g) }\end{array}$ & 95\% Confidence Interval \\
\hline Maize & $-0.036^{* * *}$ & {$[-0.039,-0.033]$} & $-£ 3.27^{* * *}$ & {$[-3.50,-3.04]$} \\
Sunflower & $-0.047^{* * *}$ & {$[-0.052,-0.043]$} & $-£ 4.33^{* * *}$ & {$[-4.82,-3.84]$} \\
Fat & $-0.014^{* * *}$ & {$[-0.016,-0.012]$} & $-£ 1.29^{* * *}$ & {$[-1.40,-1.19]$} \\
Berries & $-0.008^{* *}$ & {$[-0.014,-0.018]$} & $-f 0.72^{* *}$ & {$[-1.29,-0.15]$} \\
Ball & $1.98^{* * *}$ & {$[1.90,2.06]$} & $£ 1.82^{* * *}$ & {$[1.60,2.04]$} \\
Hanging & $0.76^{* * *}$ & {$[0.622,0.844]$} & $£ 0.70^{* * *}$ & {$[0.58,0.82]$} \\
Price per 100g & $-0.011^{* * *}$ & {$[-0.012,-0.010]$} & & \\
\# of observations & 206,688 & & 206,688 & \\
\# of clusters & 12,918 & & 12,918 &
\end{tabular}

Table 8: Results of hedonic regression (conditional logit) of bird food characteristics on purchasing decisions. Confidence intervals for WTPs are based on bootstrap with 1,000 repetitions. ${ }^{*} \mathrm{p}<0.10,{ }^{* *} \mathrm{p}<0.05, * * * \mathrm{p}<0.01$

Each 'feed' coefficient represents the changing probability of selecting an alternative if one percent of the product's nut or mealworm content is substituted by the ingredient associated with the coefficient. For example, by replacing nuts or mealworms with sunflower seeds, the negative coefficient $(-0.047)$ illustrates the reduction in the likelihood of a consumer selecting this adjusted product, supposing the feed remains the same in all other respects. Table 8 also presents the willingness-to-pay measures based on these estimates. Confidence intervals are based on a bootstrap with 1,000 repetitions. The average consumer buying bird food hence has a higher willingness-to-pay for the special ingredients mealworms and nuts compared to more basic ones such as maize and sunflower seeds. The form the bird food is presented in and hence the feeding method has a substantial impact on consumers' WTP as well. 
Generally the characteristics valued highly by consumers such as mealworms and nuts would attract aesthetic birds with vulnerable qualities. Mealworms for example are a delicacy for robins (RSPB 2014). Fat or suet based products attract robins, blackbirds and tits but not dedicated seed eaters such as sparrows and pigeons. Consumers in our sample display a willingness-to-pay of about $£ 2$ and $£ 3$ for fat based food compared to maize or sunflower seeds per $100 \mathrm{~g}$, respectively. The feeding method also works as a species selection device. Tits and robins like to feed from hanging sources (BTO 2014) which is less common for blackbirds. Products prepared to be presented hanging from trees or the like attract an additional willingness-to-pay of about 70 pence per $100 \mathrm{~g}$.

\section{Result 5}

Based on a hedonic analysis of bird food purchases, consumers value nutritious ingredients and feeding methods targeting the set of species such as robins and tits that were valued highly in the discrete choice experiment.

The patterns revealed by the hedonic analysis of bird food purchases seem to be broadly consistent with some of the preferences elicited in the discrete choice experiment. In particular, Result 1 finding a clear preference over species and the part of Result 3 that captures the preference for nutritious food are supported by market data. However, making a more direct link between products and preferences over individual species and their characteristics has proven infeasible. The key obstacle lies in establishing a reliable link between product characteristics and the probability to attract a given species. While there is plenty of advice available as to which species prefer which type of food or feeder (e.g. BTO, 2014; RSPB, 2014 and Parrish's Farm, 2014) it is by no means sufficient to compute a robust mapping. Further research could close this gap. The necessary data could be generated by extending the RSPB's BGBW survey by questions about bird food used during the period of observation.

This brief inspection of the bird-feed market by no means constitutes a comprehensive external validity check for our choice experiment. Despite the limitations encountered, we 
believe this type of inspection to be useful when trying to validate hypothetical responses. The comparison was only possible because the payment vehicle used in the stated preference study was based on a real-world private good whose consumption is directly linked to both the private and public benefits of interest.

The above analysis also illustrates some advantages of hypothetical studies over a hedonic approach. The link between revealed choices in market contexts and the environmental goods consumed is often hard to quantify reliably. Moreover, the hypothetical approach allows much greater flexibility in terms of the attributes included and how they are combined than is observable in real markets. Hence, given that - as we tried in this study the weaknesses associated with stated preference techniques are minimised, they can help to shed light at issues hard to resolve using revealed preference data alone.

\section{Conclusion}

This study contributes to the still sparse literature on the value of everyday wildlife. Traditionally the focus of both natural scientists and economists has been on endangered species. While studying rare and endangered species is important, the role of nature in the everyday lives of citizens has been neglected. The role of being connected to nature is increasingly important as widespread urbanisation has resulted in few opportunities to directly engage with nature. Using the (at least in the UK) highly popular feeding of garden birds as an example, we have investigated the motivation for this behaviour by using a discrete choice experiment to elicit people's willingness to pay for different aspects of engagement with nature. The main finding in this respect is that direct consumption benefits, i.e. watching birds feed, are most important but there is also clear evidence that people feeding birds care for them beyond these purely private benefits. There are indications that feeding establishes a warden like role for the feeder towards the birds visiting her garden. Participants in our discrete choice experiment were concerned for birds they fed but were not able to watch while doing so, they cared for the nutritional value of the food, and especially so when the number of birds visiting was low. 
We tested for broad consistency of our results with a hedonic analysis of real bird food purchases from a UK producer and retailer. As in the discrete choice experiment consumers clearly value nutrition and prefer bird food that targets specific attractive species such as robins and blue tits. However, deriving more specific valuations of species or families was not possible due to difficulties of establishing a clear link between products bought and birds fed.

We see the main contribution of our paper as drawing attention to the benefits, often neglected by policy makers and environmental commentators, that people derive from interaction with everyday wildlife. The warden-like role that such interactions allow people to take on may be a significant source of subjective well-being. The policies required to meet people's desires for such engagement may be very different from those that are aimed at conserving endangered species or wild landscapes.

\section{References}

Adamwicz, V., Boxall, P., Williams, M., \& Louviere, J. (1998). Stated preference approaches to measuring passive use values. American Journal of Agricultural Economics, 80, 64-75.

Andreoni, J. (1990). Impure altruism and donations to public goods: a theory of warm-glow giving. The Economic Journal, 464-477.

Bateman I., Carson R., Day B., Hanemann M., Hanley N., Hett T., Jones-Lee M., Loomes G.,, Mourato S., Ozdemiroglu E., Pearce D., Sudgen R. \& Swanson J. (2002). Economics Valuation with Stated Preference Techniques: A Manual. Edward Elgar Publishing.

Bateman, I. J., Burgess, D., Hutchinson, W. G., \& Matthews, D. I. (2008). Learning design contingent valuation (LDCV): NOAA guidelines, preference learning and coherent arbitrariness. Journal of Environmental Economics and Management, 55(2), 127-141.

Bateman, I. J., Day, B. H., Jones, A. P., \& Jude, S. (2009). Reducing gain-loss asymmetry: a virtual reality choice experiment valuing land use change. Journal of Environmental Economics and Management, 58(1), 106-118.

Bennett, J., \& Blamey, R. (Eds.). (2001). The choice modelling approach to environmental valuation. Edward Elgar Publishing.

BTO (2014) A-Z of garden birds, British Trust for Ornithology, http://www.bto.org/volunteer-surveys/gbw/gardens-wildlife/garden-birds/a-z-gardenbirds (last accessed: 24.4.2015) 
Christie, M., Hanley, N., Warren, J., Murphy, K., Wright, R., \& Hyde, T. (2006). Valuing the diversity of biodiversity. Ecological economics, 58(2), 304-317.

Clucas, B., Rabotyagov, S., \& Marzluff, J. M. (2015) How much is that birdie in my backyard? Urban Ecosystems, 18, 251-266

Davies, Z. G., Fuller, R. A., Loram, A., Irvine, K. N., Sims, V., \& Gaston, K. J. (2009). A national scale inventory of resource provision for biodiversity within domestic gardens. Biological Conservation, 142(4), 761-771.

Diederich, J., \& Goeschl, T. (2013). To Give or Not to Give: The Price of Contributing and the Provision of Public Goods (No. w19332). National Bureau of Economic Research.

Diener, E., \& Biswas-Diener, R. (2011). Happiness: Unlocking the mysteries of psychological wealth. John Wiley \& Sons.

Dolan, P., Peasgood, T., \& White, M. (2008). Do we really know what makes us happy? A review of the economic literature on the factors associated with subjective well-being. Journal of Economic Psychology, 29(1), 94-122.

Dunn, R. R., Gavin, M. C., Sanchez, M. C., \& Solomon, J. N. (2006). The pigeon paradox: dependence of global conservation on urban nature. Conservation biology, 20(6), 1814 1816.

Dutcher, D. D., Finley, J. C., Luloff, A. E., \& Johnson, J. B. (2007). Connectivity with nature as a measure of environmental values. Environment and behaviour, 39(4), 474-493

Farmer, M. C., Wallace, M. C., \& Shiroya, M. (2011). Bird diversity indicates ecological value in urban home prices. Urban Ecosystems, 16(1), 131-144.

Frey, B. S., \& Stutzer, A. (2010). Happiness and public choice. Public Choice, 144(3-4), 557573.

Gaston, K. J., \& Fuller, R. A. (2008). Commonness, population depletion and conservation biology. Trends in Ecology \& Evolution, 23(1), 14-19.

Gibbons, S., Mourato, S., \& Resende, G. M. (2014). The amenity value of English nature: a hedonic price approach. Environmental and Resource Economics, 57(2), 175-196.

Hanley, N., MacMillan, D., Wright, R. E., Bullock, C., Simpson, I., Parsisson, D., \& Crabtree, B. (1998). Contingent valuation versus choice experiments: estimating the benefits of environmentally sensitive areas in Scotland. Journal of Agricultural Economics, 49(1), 1-15.

Hanley, N., Wright, R. E., \& Adamowicz, V. (1998). Using choice experiments to value the environment. Environmental and Resource Economics, 11(3-4), 413-428.

Hole, D. G., Whittingham, M. J., Bradbury, R. B., Anderson, G. Q., Lee, P. L., Wilson, J. D., \& Krebs, J. R. (2002). Agriculture: widespread local house-sparrow extinctions. Nature, 418(6901), 931-932. 
Hoyos, D. (2010). The state of the art of environmental valuation with discrete choice experiments. Ecological Economics, 69(8), 1595-1603.

Inger, R., Gregory, R., Duffy, J. P., Stott, I., Voříšek, P., \& Gaston, K. J. (2015). Common European birds are declining rapidly while less abundant species' numbers are rising. Ecology letters, 18(1), 28-36.

Jacobsen, J. B., Boiesen, J. H., Thorsen, B. J., \& Strange, N. (2008). What's in a name? The use of quantitative measures versus 'Iconised' species when valuing biodiversity. Environmental and Resource Economics, 39(3), 247-263.

Johnson, T. D. (2011). Pets can be a prescription for happier, healthier life. Nation's Health, $40,10-32$.

Jones, D. (2011). An appetite for connection: why we need to understand the effect and value of feeding wild birds. Emu, 111(2), i-vii.

Kontoleon, A., \& Swanson, T. (2003). The willingness to pay for property rights for the Giant Panda: can a charismatic species be an instrument for nature conservation?. Land Economics, 79(4), 483-499.

Lancaster, K. J. (1966). A new approach to consumer theory. The Journal of Political Economy, 132-157.

List, J. A. (2003). Does market experience eliminate market anomalies?. Quarterly Journal of Economics, 118(1), 41-72.

Loomis, J. B., \& White, D. S. (1996). Economic benefits of rare and endangered species: summary and meta-analysis. Ecological Economics, 18(3), 197-206.

Louviere, J. J., Hensher, D. A., \& Swait, J. D. (2000). Stated choice methods: analysis and applications. Cambridge University Press.

McFadden, D. (1974). Conditional Logit Analysis of Qualitative Choice Behaviour. In: Zarembka, P. (ed). Frontier of Econometric Academic Press, New York, 105 - 142.

Metrick, A., \& Weitzman, M. L. (1996). Patterns of behavior in endangered species preservation . Land Economics, 72(1), 1-16.

Miller, J. R., \& Hobbs, R. J. (2002). Conservation where people live and work. Conservation biology, 16(2), 330-337.

Morse-Jones, S., Bateman, I. J., Kontoleon, A., Ferrini, S., Burgess, N. D., \& Turner, R. K. (2012). Stated preferences for tropical wildlife conservation amongst distant beneficiaries: charisma, endemism, scope and substitution effects. Ecological Economics, 78, 9-18.

Navrud, S., \& Mungatana, E. D. (1994). Environmental valuation in developing countries: the recreational value of wildlife viewing. Ecological Economics, 11(2), 135-151. 
Norfolk County Council (2013) Norfolk's Story, Version 4.0, available from insight@norfolk.org.uk

Norfolk Insights (2013), Population Statistics, access to the 2011 Census data for the region, http://www.norfolkinsight.org.uk/profiles/profile?profileld=18\&geoTypeld= $=$ (Last accessed 26.04.2015)

Nunes P. \& van den Bergh J. (2001). Economic valuation of biodiversity: sense or nonsense? Ecological Economics, 39, 203-222.

Parrish's Farm (2014) Feeding tips, http://www.parrishsfarm.org.uk/feedingtips.html (last accessed: 24.4 .2015$)$

Perino, G., Andrews, B., Kontoleon, A., \& Bateman, I. (2014). The value of urban green space in Britain: a methodological framework for spatially referenced benefit transfer. Environmental and Resource Economics, 57(2), 251-272.

Rappe, E. (2005). The influence of a green environment and horticultural activities on the subjective well-being of the elderly living in long-term care. Yliopistopaino, Helsinki.: University of Helsinki.

Rolfe, J., \& Bennett, J. (2009). The impact of offering two versus three alternatives in choice modelling experiments. Ecological Economics, 68(4), 1140-1148.

Rosen H. \& Small K. (1979). Applied Welfare Economics with Discrete Choice Models. NBER Working Paper 319 (Feb).

RSPB (2014) Which bird food, Royal Society for the Protection of Birds, http://shopping.rspb.org.uk/which-bird-food (last accessed: 24.4.2015)

Scheufele, G., \& Bennett, J. (2012). Response strategies and learning in discrete choice experiments. Environmental and Resource Economics, 52(3), 435-453.

Swait, J., \& Adamowicz, W. (1996). The effect of choice environment and task demands on consumer behavior: discriminating between contribution and confusion. Department of Rural Economy, Faculty of Agriculture \& Forestry, and Home Economics, University of Alberta.

Tinbergen, N. (1953). The herring gull's world (pp. 176-181). London: Collins.

White, P. C., Gregory, K. W., Lindley, P. J., \& Richards, G. (1997). Economic values of threatened mammals in Britain: a case study of the otter Lutra lutra and the water vole Arvicola terrestris. Biological Conservation, 82(3), 345-354. 
Appendix A: Rankings of the RPSB Big Garden Bird Watch (BGBW) Survey 2012

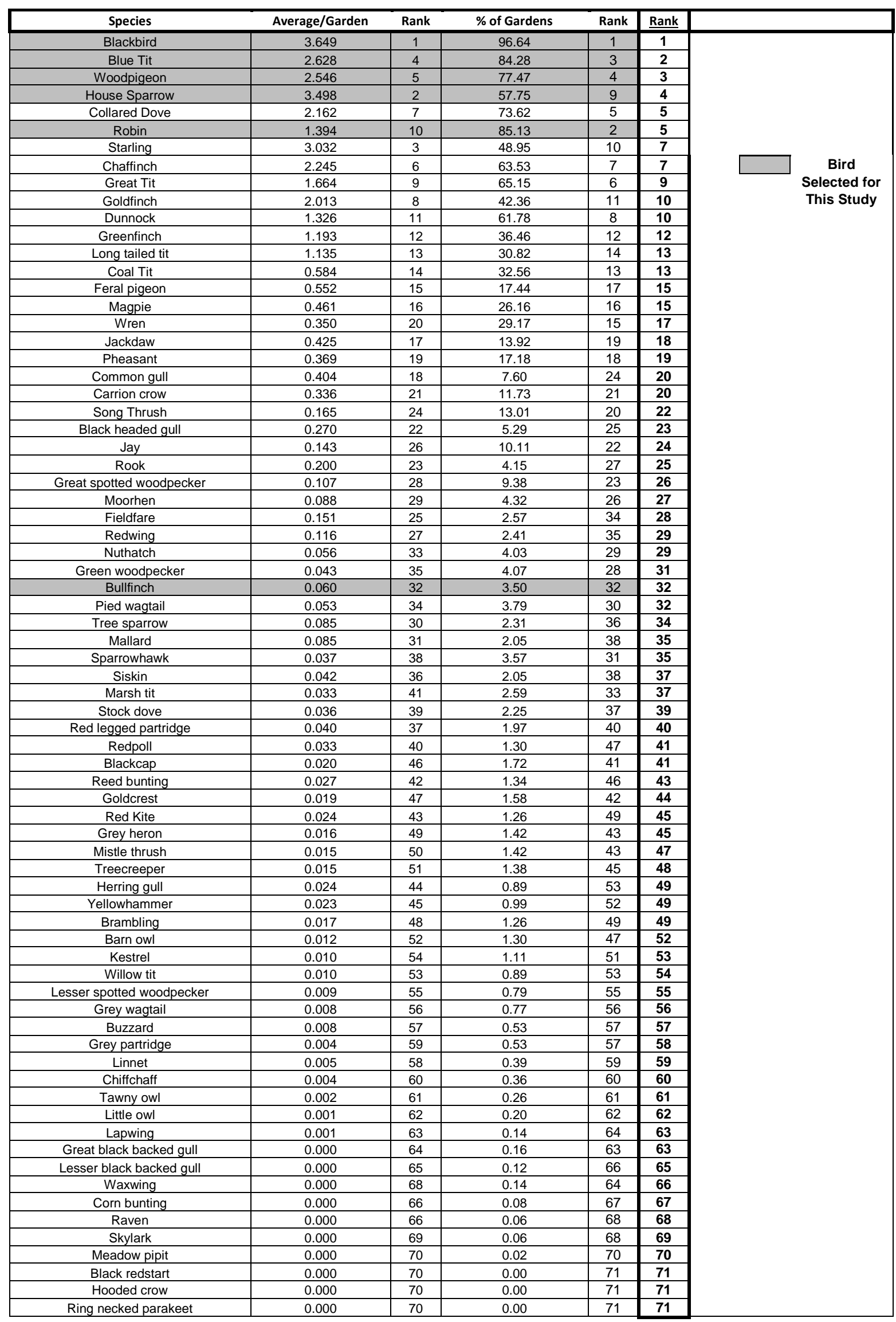




\section{Appendix B: Survey Instructions Key}

You will need to use this to understand the cases you are presented with

\section{$\underline{\text { Species }}$}

Cases will indicate the type and frequency of species that may come to your garden. Frequency estimations are described in the table below:

\begin{tabular}{|c|c|}
\hline Rating & Description \\
\hline & $\begin{array}{c}\text { This species will not come to your } \\
\text { garden }\end{array}$ \\
\hline & $\begin{array}{c}\text { Expect 1 bird of this species to come to } \\
\text { your garden }\end{array}$ \\
\hline & $\begin{array}{c}\text { Expect an average of between } \mathbf{2} \text { and } \mathbf{5} \\
\text { birds of this species to come to your } \\
\text { garden }\end{array}$ \\
\hline
\end{tabular}

This is the frequency estimation for each time the food is dispensed. The average person would expect to obtain 20 feeding opportunities from each bag.

\section{Visibility}

If instead of being shown in full colour, a bird is shown faded, this will mean these birds will feed in your garden from the food you have dispensed, but you will not see them. An example illustrates this below. Here, whilst 2-5 of these birds will feed in your garden, you will only actually see one of them.

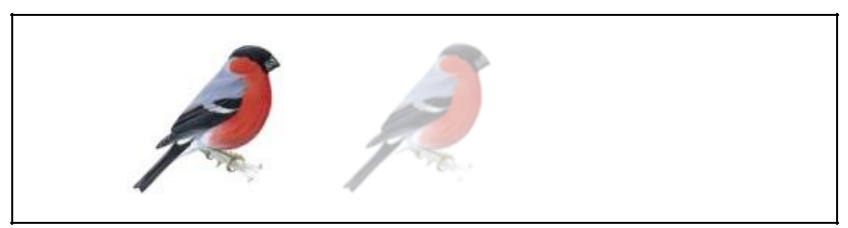


Here are the six different species that may be seen as a consequence of dispensing bird food. The species appear below in their natural plumage (colouring) and will always appear in the same position on a choice card if present.

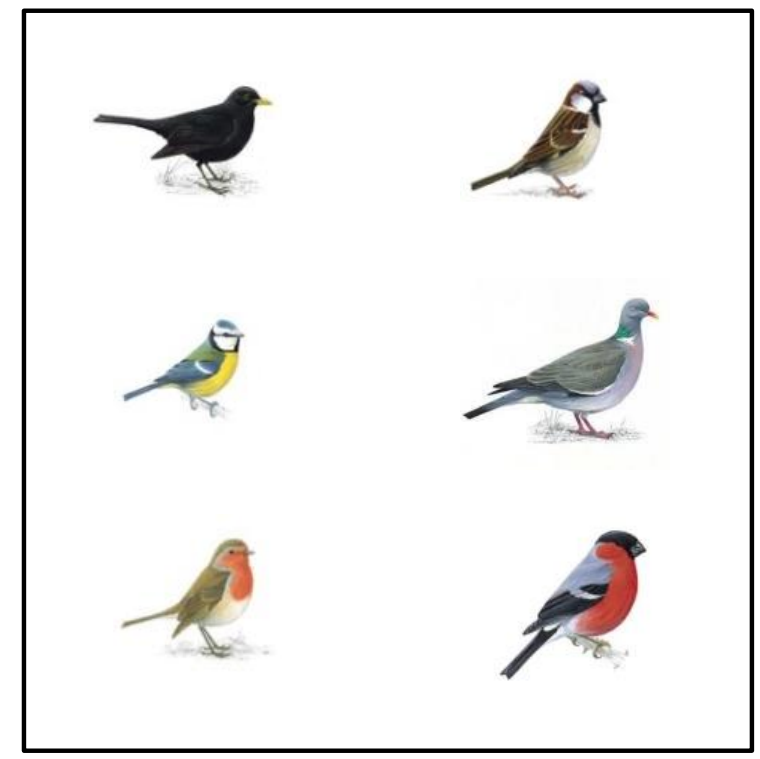

\section{Nutrition}

Each option has a $\hat{\xi}$ rating. These act like 'Hotel ratings', ranging from one-star to three-star categories. A one-star option will provide basic nourishment, and options with more stars will provide a greater level of nutrition to each bird which is fed.

\section{Price and Donations}

The price of an option represents the amount you would have to pay to obtain that seed bag[Please remember no actual purchases will be made as part of this survey].

In some cases, this price includes a donation. This donation contributes toward habitat restoration which aims to raise the population of the Bittern in East Anglia.

The Bittern is a very rare and elusive species, and over two thirds of its remaining UK population live among East Anglian reedbeds currently. If a donation is being made, this will be clearly indicated on the choice case.

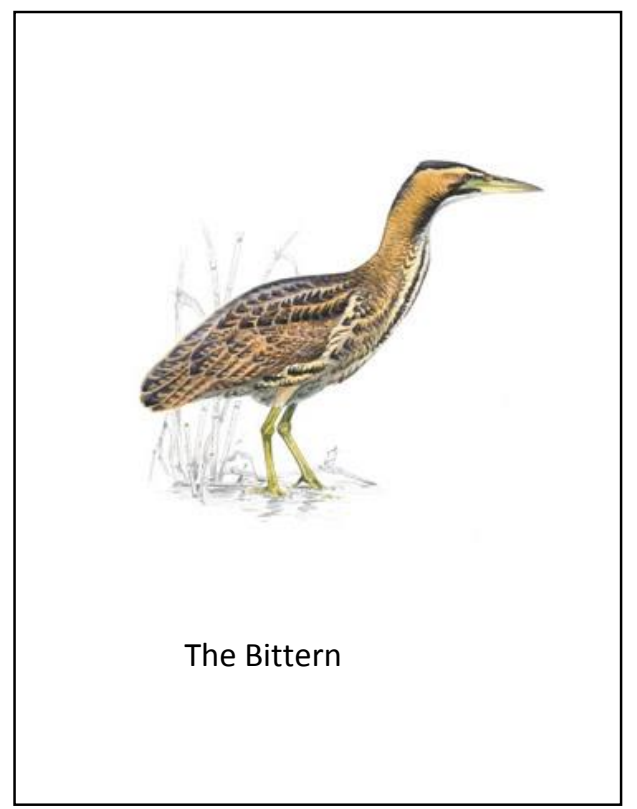


Appendix C: Bird Quiz Sheet

\begin{tabular}{|c|c|}
\hline Possible Bird Names & Letter \\
\hline \multicolumn{2}{|l|}{ Chaffinch } \\
\hline \multicolumn{2}{|l|}{ Robin } \\
\hline \multicolumn{2}{|l|}{ Grey Heron } \\
\hline \multicolumn{2}{|l|}{ Lesser-Spotted Woodpecker } \\
\hline \multicolumn{2}{|l|}{ Blue Tit } \\
\hline \multicolumn{2}{|l|}{ Woodpigeon } \\
\hline \multicolumn{2}{|l|}{ Blackbird } \\
\hline \multicolumn{2}{|l|}{ Bullfinch } \\
\hline \multicolumn{2}{|l|}{ Song Thrush } \\
\hline \multicolumn{2}{|l|}{ Kestrel } \\
\hline \multicolumn{2}{|l|}{ Collared Dove } \\
\hline \multicolumn{2}{|l|}{ Dunnock } \\
\hline \multicolumn{2}{|l|}{ Mallard } \\
\hline \multicolumn{2}{|l|}{ Tree Sparrow } \\
\hline \multicolumn{2}{|l|}{ House Sparrow } \\
\hline Great Tit & \\
\hline
\end{tabular}




\section{$\underline{\text { Respondent Survey }}$}

1. Which of these best describes the garden space at the place where you live?

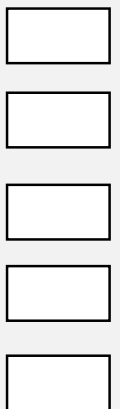

No Garden

Small Private Garden (area less than a tennis court)

Large Private Garden (area larger than a tennis court)

Farmland / Fields

Communal Gardens

2. Which of these describe the food you put out for the birds (Tick all that apply)?

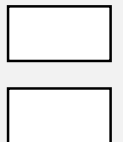

I do not feed the birds

Leftover food

Bird food

Other (please specify)

3. If you do feed them, at what times of year do you do so and how often?

\begin{tabular}{|c|c|c|c|}
\cline { 2 - 4 } \multicolumn{1}{c|}{ Never } & Occasionally & Regularly \\
\hline Winter & & & \\
\hline Spring & & & \\
\hline Summer & & & \\
\hline Autumn & & & \\
\hline
\end{tabular}

4. In the last 12 months, have you contributed to an environmental charity?

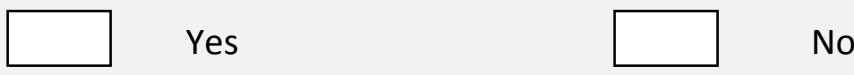


5. Please rate each of the options below, which represent your reasons, if any, for feeding birds: ( 1 = Not important to me; 5 = Very important to me)

Enjoyment from looking at them

$\begin{array}{lllll}0 & 0 & 0 & 0 & 0 \\ 1 & 2 & 3 & 4 & 5\end{array}$

I feel they need the extra food

$\begin{array}{ccccc}0 & 0 & \bigcirc & 0 & \bigcirc \\ 1 & 2 & 3 & 4 & 5\end{array}$

Help towards bird populations

$\begin{array}{ccccc}0 & \bigcirc & \bigcirc & \bigcirc & \bigcirc \\ 1 & 2 & 3 & 4 & 5\end{array}$

It makes me feel good to think I am helping

$\begin{array}{ccccc}\bigcirc & \bigcirc & \bigcirc & \bigcirc & \bigcirc \\ 1 & 2 & 3 & 4 & 5\end{array}$

Throwing leftover food in the bin is a waste

$\begin{array}{ccccc}\bigcirc & \bigcirc & \bigcirc & \bigcirc & \bigcirc \\ 1 & 2 & 3 & 4 & 5\end{array}$

6. Gender: $\square$ Male
\[ \text { Female } \]
$\square$

\begin{tabular}{|c|c|c|}
\hline \multirow[t]{3}{*}{ 7. Age: } & $18-25 y r s$ & $26-35 y r s$ \\
\hline & 36- 45yrs & $46-55 y r s$ \\
\hline & $56-65 y r s$ & $65 y r s+$ \\
\hline
\end{tabular}

8. What is your approximate annual (monthly) post-tax household income?

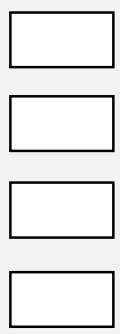

Below $£ 20,000$ (Below $£ 1,667$ )

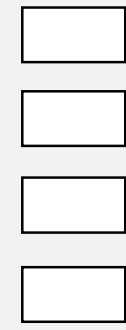

$£ 60,000-£ 69,999(£ 5,000-£ 5,833)$

$£ 20,000-£ 29,999(£ 1,668-£ 2,499)$

$£ 70,000-£ 79,999(£ 5,834-£ 6,666)$

$£ 30,000-£ 39,999(£ 2,500-£ 3,333)$

$£ 80,000-£ 89,999(£ 6,667-£ 7,499)$

$£ 40,000-£ 49,999(£ 3,334-£ 4,166)$

Above $£ 90,000$ (Above $£ 7,500$ )

$£ 50,000$ - £59,999 (£4,167 - £4,999)

Prefer not to disclose

This is the end of the survey! Thanks again for your participation; both your responses and time have been invaluable and essential to the research. 